\title{
Motorized Transportation, Social Status and Adiposity
}

The China Health and Nutrition Survey

Li Qin, PhD, Ronald P Stolk, MD, PhD, Eva Corpeleijn, PhD

From the Department of Epidemiology, University Medical Center of Groningen, University of Groningen, Groningen, The Netherlands

Address correspondence to: Li Qin, PhD, Department of Epidemiology, University of Medical Center Groningen, PO Box 30.001, 9700 RB Groningen, The Netherlands. E-mail: e.corpeleijn@umcg.nl 
Background: Increased dependence on motorized transportation may contribute to obesity. Countries in rapid socioeconomic transitions, like China, provide an opportunity to investigate such association.

Purpose: The hypotheses were examined: that the increased dependence on motorized transportation is related to adiposity; and that this effect will be more pronounced in those adults with high socioeconomic status (SES) or living in urban regions.

Methods: Data from the longitudinal China Health and Nutrition Survey conducted from 1997 till 2006 ( $n=3,853$, aged 18 55yrs at baseline, 52\%women, 7.8years follow-up) were used to examine the association between motorization (none, 1-5years, >5years) and the changes in body weight and waist circumference (WC) by using multivariate regression. SES factors were obtained from questionnaires. Data were analyzed in 2010.

Results: Use of motorized transportation >5years was related with $\sim 1.2 \mathrm{~kg}$ larger weight gain $(\mathrm{P}=0.006)$ and $\sim 1.0 \mathrm{~cm}$ larger $\mathrm{WC}$ gain $(\mathrm{P}=0.017)$ in men, when compared with the nonmotorized group and adjusted for baseline age, anthropometry, dietary intake and follow-up time. These changes were slightly more pronounced in men with higher income or from rural areas, but the difference was not significant. In women, the tendency for motorization with weight gain was less pronounced $(+1.1 \mathrm{~kg}, \mathrm{P}=0.008)$. Low education and high income were the most predominant factors. In 2006, motorization was associated with a 1.3-fold higher odds ratio for obesity $\left(\mathrm{P}_{\text {trend }}=0.054\right)$ and abdominal obesity $\left(\mathrm{P}_{\text {trend }}=0.047\right)$ in men, and a two-fold higer OR of obesity in women $\left(\mathrm{P}_{\text {trend }}<0.001\right)$.

Conclusion: Motorized transportation was related with an increase in adiposity in the Chinese population, particularly in men. 


\section{Introduction}

With the increasing pandemic of obesity around the world, developing countries also face this health burden. In 2002, about 195 million Chinese adults were estimated to be obese with a $\mathrm{BMI} \geq 25 \mathrm{~kg} / \mathrm{m}^{2} .{ }^{1}$ The percentage of overweight in China has increased by $50 \%$ over the past decade. ${ }^{2}$ Rapid socioeconomic, demographic and nutritional transitions promoting unhealthy lifestyles and behavioural changes may drive the weight gain in this developing population. ${ }^{3-5}$

Walking or cycling as a form of "active transportation" is inversely associated with obesity and may therefore have the potential to improve public health. ${ }^{6-10}$ In developed countries like the USA, Canada, Sweden and Australia, motorized transportation has been established as a dominant sedentary travel pattern for many decades. Several studies have confirmed that driving a car is associated with obesity in developed countries. ${ }^{11-14}$ In China, the rapid urbanization evokes equally rapid shifts towards a more sedentary lifestyle with transitions away from an agricultural economy and towards the acquisition of new technology. ${ }^{15,16}$ For example, active transportation covered up to $80 \%$ of daily travel in China till the 1990's, but that situation declined dramatically thereafter. ${ }^{17,18}$ The number of urban households possessing a private car increased about 19 -fold from 1996 to $2006 .{ }^{19}$ In 2022 , China's vehicle population might reach 419 million. ${ }^{20}$ Such a rapid increase may likely reduce the need of "active transport" and evoke the development of obesity.

In addition, socioeconomic factors may play an important role in the development of obesity. People who have high socioeconomic status (SES) or live in urbanized areas, may be the first to have access to energy-dense foods, to have a declined work related physical activity and to have access to motorized transport in a developing country. ${ }^{15,21}$ Based on the findings from the limited work done in China previously, it is hypothesized that: 1) the use of motorized 
transport is independently associated with changes in body weight and waist circumference, 2) this effect will be more pronounced in those with a high income or who live in urban regions, and 3) the use of motorized transport is independently associated with the current obesity status. This was studied in Chinese adults (age 18 55y at baseline) who participate in the longitudinal China Health and Nutrition Survey.

\section{Methods}

\section{Participants}

The China Health and Nutrition Survey (CHNS) began in 1989. It is an ongoing international collaborative project between the Carolina Population Centre at the University of North Carolina, United States and the National Institute of Nutrition and Food Safety at the Chinese Centre for Disease Control and Prevention, China. The study was designed to examine the effects of health, nutrition and family planning policies, and to see how the social and economic transformation of the Chinese society is affecting the health and nutritional status of its population. The survey took place over a three-day period using a multistage, random cluster process to draw a sample of about 4,400 households in nine provinces that varied substantially in geography, economic development, public resources, and health indicators. ${ }^{22}$

The data of the present study was prospectively collected in the survey year of 1997, 2000, 2004 and 2006. In 1997, 6,418 participants of 18-55 years old without pregnancy or physical disability were included. In total, 5,240 participants completed at least one questionnaire in 2000, 2004 or 2006 ( 82\% follow-up, an average 7.8years follow-up) (Appendix A, www.ajpmonline.org). Of the 5240 participants available for follow-up, 3,853 completed every questionnaire during follow-up, had no missing information on occupational physical activity, SES or anthropometric measures, and remained in the final analysis. 


\section{Assessment of Motorization}

The possession of motorized vehicles was defined as possessing motorcycles, tractors or cars at household level by using questionnaires. Every participant was assumed from the same household had the equal ownership of motorized vehicles. Participants were categorized as follows: those who possessed motorized vehicles from1997 till 2000 were defined as motorized for 3 years, those with vehicles from 2000 to 2004 as motorized for 4 years, and those with vehicles from 2004 to 2006 as motorized for 2 years. Based on these time frames and registration in each survey year (1997, 2000, 2004 and 2006), the total duration of possessing motorized vehicles was calculated, categorized as: non-motorized, motorized 1 5 years, and motorized $>5$ years.

\section{Assessment of other Variables}

Occupational and other physical activity: occupational physical activity was categorized as light (e.g. sedentary job, sitting, office work), moderate (e.g. driver, electrician) or heavy (e.g. farmer, athlete, dancer, steel worker or lumber). The total weekly energy expenditure during work was calculated by multiplying time spent and metabolic equivalent task scores(METs) as 2.0, 4.0 and 6.0 METs h, respectively for light, moderate and heavy occupational physical

activity. ${ }^{17}$ Sex-specified tertiles of occupational physical activity were defined. Only a limited percentage of participants attended leisure time physical activity. Leisure time physical activity was defined as whether or not attending such activities.

Living regions: urban or rural region was used as a dichotomous variable to distinguish regional differences, such as economic development, infrastructure and social environment. 
Socio-economic status: individual net income included the sum of all sources of income and was divided into sex-specified quantiles. In Figure 1, income was categorized by the median (low and high). Education was categorized as primary education or less, low middle school education, upper middle/technical school education, and college/university education.

Lifestyle factors: smoking was defined as never smoked, ex-smoker, $<10$ cigarettes/day, and $\geq 10$ cigarettes/day. Alcohol consumption was defined as never drinking beer/any other alcoholic beverage last year, drinking less than 2 times/week, and more than 3 times/week. Due to the low prevalence of smoking and drinking among women (Appendix A), these two variables were not adjusted for statistical analysis in women. Dietary intake was collected by nutritionists using 24-hour recalls over 3 consecutive days with the start day randomly allocated from Monday to Sunday, and daily total energy(kcal/day) and fat(g/day) intake were calculated.

Region was assessed at the time of inclusion in the study. To obtain the best estimate of longterm habitual dietary intake, occupational physical activity and income, the cumulative average of the variable was taken. For education, smoking and alcohol drinking, the most recent information was assessed.

\section{Assessment of Adiposity}

Obesity was defined as body mass index $(\mathrm{BMI}) \geq 25 \mathrm{~kg} / \mathrm{m}^{2}$ based on the suggested standard for the Chinese population. ${ }^{23}$ According to the same guideline, abdominal adiposity was defined as waist circumference (WC) $\geq 90 \mathrm{~cm}$ for men and $\mathrm{WC} \geq 80 \mathrm{~cm}$ for women. Changes in body weight and $\mathrm{WC}$ were calculated as the average difference of weight $(\mathrm{WC})$ in $\mathrm{kg}(\mathrm{cm})$ measured at baseline and each available measure during follow-up. 


\section{Statistical Analyses}

Men and women were presented separately due to the differences in lifestyle and socioeconomic factors (Appendix A). Multivariate linear regression was used to assess the linear associations between motorization, SES indicators and changes in weight and WC, or current BMI and WC (as assessed by recent measures). To assess whether interaction was present, the likelihood ratio test was used to compare the significant difference of regression models with or without interaction term. Multivariate logistical regression was used to assess the odds ratio (OR) for adiposity in association with motorization.

Of the 5,240 participants in follow-up, motorization status, SES and/or anthropometric measures were not available for $26.5 \%$ participants. As an additional sensitivity test, the analyses were repeated by using the complete data with multiple imputation(10 imputations) for the data that were missing in these participants. The missing data were predicted based on a regression model that included baseline and end-point BMI/WC, baseline and end-point motorization, follow-up time, education, income, occupational physical activity, age, energy and fat intake. Missing values were imputed and 10 complete data sets were analyzed separately, and pooled the results into single estimated beta coefficients. Significance of all analyses and adjusted OR was based on two-sided 95\% confidence interval. An alpha level of 0.05 for all statistical tests was used. Statistics were performed in Stata Version 11.0 (STATA, College Station, TX, USA).

\section{Results}

Table 1 shows the characteristics of 3,853 participants. About $46 \%$ participants were nonmotorized during the $\sim 7.8$ years follow-up; $27 \%$ possessed motorized vehicles for 1 5years, 
and $27 \%$ possessed vehicles $>5$ years. Those who possessed motorized vehicles $>5$ years had a higher WC at baseline, and showed the highest prevalence of (abdominal) obesity at the end of follow-up. Men (motorized>5years) tended to have a 2-fold higher weight gain than the non-motorized group $(P=0.04)$. Motorization was also related to socio-economic factors, such as education, income (men) and rural residency (women).

Table 2 shows that motorization $>5$ years was independently related with larger weight gain $(2.5 \pm 0.7 \mathrm{~kg}, P=0.009)$ and $\mathrm{WC}$ gain $(3.6 \pm 0.7 \mathrm{~cm}, P=0.016)$ in men, compared with the nonmotorized group $(1.3 \pm 0.5 \mathrm{~kg}$ weight and $2.6 \pm 0.5 \mathrm{~cm}$ waist gain), when adjusted for age, baseline anthropometry, dietary factors and follow-up time. Heavy occupational physical activity was importantly associated with a smaller increase in weight $(1.5 \pm 0.6 \mathrm{~kg}, P=0.048)$ and WC $(2.0 \pm 0.6 \mathrm{~cm}, P<0.001)$ in men, compared with light activity $(2.4 \pm 0.6 \mathrm{~kg}$ weight and $3.9 \pm 0.6 \mathrm{~cm}$ WC gain). High income and high education were associated with increased weight gain in men. In women, the associations were less pronounced. Although longer motorization showed a tendency of more weight gain $(P=0.008)$ but not WC gain $(P=0.76)$, education and income were more strongly related with weight (WC) change. In particular high education was protective against waist gain in women.

Since the possession of motorized vehicles could be a proxy of SES or urbanicity, the association between motorization and obesity may vary with region and income. Figure 1 shows that the impact of motorization on weight gain was significant in men living in rural regions $(P=0.019)$, but not in urban regions $(P=0.38)$. However, no significant effect modification by living region was found between region and motorization for weight $(P=0.29$ for interaction) and waist gain $(P=0.78$ for interaction) from the likelihood ratio test. Figure 2 shows that the impact of motorization on weight $(P=0.054)$ and $\mathrm{WC}$ gain $(P=0.006)$ was 
significant in men having high income, but not low income. No significant effect modification by income was found between income and motorization for weight $(P=0.15$ for interaction $)$ and waist gain $(P=0.11$ for interaction $)$.

The association of motorization with the current obesity status at 2006 is presented in Table 3 . The odds ratio (OR) of obesity was 1.30 (95\%CI: 0.97-1.74) and $1.93(1.50-2.49)$ for the motorized>5years group in men and women. The association of SES and region with the current obesity status was presented in Appendix B (www.ajpmonline.org). Income ( $p=0.03$ for interaction $)$ and education $(P=0.06$ for interaction $)$ tended to modify the association between motorization and current BMI in women, with the impact of motorization being stronger in women having low income or education (data not shown).

As an additional sensitivity test to assess whether the results were influenced by the missing values, $26.5 \%$ of 5,240 participants with missing values were imputed and performed all analyses in the 10 complete data sets separately, and pooled the results into single estimated beta coefficients. Compared with the presented results, the imputed results did not change appreciably and did not influence the conclusions (data not shown).

\section{Discussion}

A longer motorization period was independently related with a larger gain in weight and WC in Chinese men after 7.8 years follow-up, when compared with those who never owned motorized vehicles. The gain in weight and WC was slightly more pronounced in men with a higher income or from rural areas, but the difference compared with low income or urban areas was not significant. In women, motorization was only related to weight gain and not waist gain, but the tendency was less pronounced than in men. A longer motorization period 
in the past was also independently associated with a higher OR of current adiposity in men and women.

The present study can be compared with a previous study by Bell et al. ${ }^{24}$ They suggested that the possession of motorized vehicles was associated with an increase in obesity and weight gain in Chinese men, based on CHNS data from 1989 to 1997. However, few people acquired motorized vehicles between 1989 and 1993, and less than $13 \%$ of the participants had motorized vehicles before $1997 .{ }^{24}$ Due to the possible time lag between the dependence on motorized vehicles and the onset of obesity, the authors at that time might not have been able to fully conclude that motorization independently contributed to an increased obesity rate.

The present analysis covers a rapidly changing period from 1997 till 2006, and the duration of motorization may give better prospective information than vehicles ownership defined as a dichotomous variable. Another difference is that WC was additionally measured at the onset of the present study, and it appears to be very important to assess obesity-related metabolic risks in the Chinese population. ${ }^{25}$ It was found that Chinese men (motorized $>5$ years) had independently gained more weight and WC than those who never possessed vehicles during the follow-up, and were more likely to be (abdominally) obese in 2006. Such an association suggests that longer motorization contributes to the obesity status. These associations were adjusted for income and education, and motorization as a proxy for socioeconomic wealth had only marginal effects on the strength of the association. However, the adjustments were not equal to controlling for wealth, and some degree of residual confounding can not be excluded. With regard to women, the association between motorization and weight gain was less pronounced, and it is difficult to draw a firm conclusion. A possible explanation is that men were more likely to be the predominant users of motorized vehicles in Chinese households. ${ }^{24}$ 
The potential influence of the regional differences was investigated, assuming that urban residents may be the first to experience changes, leading to "modernized" lifestyles, the early access to motorized transportation and a high obesity rate. In the present study, rural residents tended to gain somewhat more weight and WC than urban residents, but the differences were not pronounced. Furthermore, living in the rural regions had a bit more stronger impact on the association between motorization and weight change, although the findings do not support the significant modification of this association by living region. One of the possible explanations is that the regional variation was diminished by the continuous development in some rural regions. Therefore, rural residents might also have experienced increased income and motorization, and a larger increase in obesity than the urban in the past decades. ${ }^{2,26-28}$ However, the misclassification of the urban-rural dichotomous variable, which might not catch the full variation in health by the heterogeneity emerging in these areas due to the degree of urbanicity, ${ }^{27}$ can not be completely ruled out.

The social inequality in adiposity differs in men and women, which could be explained by the current stage of development. A high SES, as proxied by high income and education, was positively associated with adiposity in men. However, high education was inversely and strongly associated with adiposity in women, which is in line with previous findings in women from rapidly developing countries. ${ }^{28-32}$ Income effects were absent in women. This pattern was consistent with findings from Brazilian women, especially with those from more economically developed parts. ${ }^{31}$ Furthermore, motorization only tended to be more positively associated with current BMI in women with low SES in the present study. In the early stage of economic development, as the level of urbanization increases, the burden of obesity might shift from the high SES towards the low SES first in the women from the developing 
countries. ${ }^{26,32,33}$ It is important to realize that social inequality in adiposity is in transition due to the levels of development and urbanization. ${ }^{28,30}$

The major strengths of this study include the use of prospective CHNS data from 1997 till 2006, covering a time frame in China with large changes. It has provided insight into the association between motorization and SES with adiposity. This study also has potential limitations. The duration of motorization might be misclassified by the household possession of motorized vehicles, and the true impact of motorization on adiposity was likely attenuated. A well-informed prospective study is needed to further investigate the mechanism of to what extend a reduced energy expenditure due to motorization contributes to the changes in body composition. Although the present results suggest a significant relationship between motorization and larger weight/waist gain, the results are not sufficient to prove causality. For instance, people may choose the transportation patterns due to other unmeasured factors, such as socioeconomic wealth or the accessibility to modern infrastructure. Third, domestic physical activity was not assessed, which was presumably important for daily energy expenditure in Chinese women, although a recent study performed in the same population did not find that reduced domestic physical activity resulted in higher body weight in women. ${ }^{16}$ Finally, it has been found that changes in dietary patterns were strongly associated with adiposity in Chinese population. ${ }^{26,34}$ Although dietary intake was adjusted for the present models, residual confounding can not be excluded.

In conclusion, motorization was related with the increase in adiposity in this Chinese population in an average 7.8-year follow-up, in particularly for men. It did not vary considerably with income or living region. For women, education was a more important determinant for weight gain than motorization. However, the continuous socioeconomic 
transition may alter and differentiate the social inequality in adiposity of men and women, and influence the types of physical activity participation in China. ${ }^{4,17,35}$ Assuming that the sustained development affects all Chinese inhabitants, a small increase in active transport may have the potential to prevent obesity in this population. ${ }^{4,36,37}$ An active lifestyle should be promoted for all, combined by increased active transportation patterns and leisure time physical activity, to achieve the best health benefits. 


\section{Acknowledgements}

This research uses public data from China Health and Nutrition Survey (CHNS). We thank the National Institute of Nutrition and Food Safety, China Center for Disease Control and Prevention; the Carolina Population Center, University of North Carolina at Chapel Hill; the National Institutes of Health (NIH; R01-HD30880, DK056350, and R01-HD38700); and the Fogarty International Center, NIH, for financial support for the CHNS data collection and analysis files since 1989. We thank those parties, the China-Japan Friendship Hospital, and the Ministry of Health for support for CHNS 2009 and future surveys.

No financial disclosures were reported by the authors of this paper. 


\section{Figure Legends}

Figure 1. Changes in body weight and waist circumferences according to duration of motorization, stratified for gender and living regions, adjusted for baseline weight, height, age and WC (for change in WC), follow-up time, total energy and fat intake, occupational physical activity, education and income. For men, additional adjustments were made for smoking and alcohol consumption

Figure 2. Changes in body weight and waist circumferences according to duration of motorization, stratified for gender and income, adjusted for baseline weight, height, age and WC (for change in WC), follow-up time, total energy intake, fat intake, occupational physical activity, education and living region. For men, additional adjustments are made for smoking and alcohol drinking consumption 


\section{References}

1. Wu Y, . Overweight and obesity in China. BMJ. 2006;333(7564):362-363.

2. Wang Y, Mi J, Shan XY, Wang QJ, Ge KY. Is China facing an obesity epidemic and the consequences? The trends in obesity and chronic disease in China. International Journal of Obesity. 2007;31(1):177-188.

3. Bell AC, Ge K, Popkin BM. Weight gain and its predictors in Chinese adults. International Journal of Obesity. 2001;25(7):1079-1086.

4. James WP. The fundamental drivers of the obesity epidemic. Obes Rev. 2008;9 Suppl 1:613.

5. Reynolds K, Gu D, Whelton PK et al. Prevalence and risk factors of overweight and obesity in China. Obesity (Silver Spring). 2007;15(1):10-18.

6. Berrigan D, Troiano RP, McNeel T, DiSogra C, Ballard-Barbash R. Active transportation increases adherence to activity recommendations. American Journal of Preventive Medicine. 2006;31(3):210-216.

7. Besser LM, Dannenberg AL. Walking to public transit steps to help meet physical activity recommendations. American Journal of Preventive Medicine. 2005;29(4):273-280.

8. Carnall D. Cycling and health promotion. A safer, slower urban road environment is the key. BMJ. 2000;320(7239):888.

9. Pucher J, Buehler R, Bassett DR, Dannenberg AL. Walking and Cycling to Health: A Comparative Analysis of City, State, and International Data. American Journal of Public Health. 2010;100(10):1986-1992.

10. Wagner A, Simon C, Ducimetiere P et al. Leisure-time physical activity and regular walking or cycling to work are associated with adiposity and $5 \mathrm{y}$ weight gain in middleaged men: the PRIME Study. Int J Obes Relat Metab Disord. 2001;25(7):940-948. 
11. Lindstrom M. Means of transportation to work and overweight and obesity: a populationbased study in southern Sweden. Prev Med. 2008;46(1):22-28.

12. Sallis JF, Frank LD, Saelens BE, Kraft MK. Active transportation and physical activity: opportunities for collaboration on transportation and public opportunities health research. Transportation Research Part A-Policy and Practice. 2004;38(4):249-268.

13. Wen LM, Orr N, Millett C, Rissel C. Driving to work and overweight and obesity: findings from the 2003 New South Wales Health Survey, Australia. International Journal of Obesity. 2006;30(5):782-786.

14. Wen LM, Rissel C. Inverse associations between cycling to work, public transport, and overweight and obesity: Findings from a population based study in Australia. Preventive Medicine. 2008;46(1):29-32.

15. Monda KL, Gordon-Larsen P, Stevens J, Popkin BM. China's transition: the effect of rapid urbanization on adult occupational physical activity. Soc Sci Med. 2007;64(4):858870.

16. Monda KL, Adair LS, Zhai F, Popkin BM. Longitudinal relationships between occupational and domestic physical activity patterns and body weight in China. Eur J Clin Nutr. 2008;62(11):1318-1325.

17. Ng SW, Norton EC, Popkin BM. Why have physical activity levels declined among Chinese adults? Findings from the 1991-2006 China Health and Nutrition Surveys. Soc Sci Med. 2009;68(7):1305-1314.

18. Smith R. Creative destruction: Capitalist development and China's environment. New Left Review. 1997;(222):3-41.

19. National Bureau of Statistics of China. The China Statistical Yearbook 2007. 2007. Ref Type: Internet Communication 
20. Wang YS, Teter J, Sperling D. China's soaring vehicle population-even greater than forecasted. Energy Policy. 2011;39(6):3296-3306.

21. Popkin BM, Du S. Dynamics of the nutrition transition toward the animal foods sector in China and its implications: a worried perspective. J Nutr. 2003;133(11 Suppl 2):3898S$3906 S$.

22. CHNS. China Health and Nutrition Survey. 2011. (http://www.cpc.unc.edu/projects/china). (Accessed 2011)

23. WHO/IASO/IOTF. The Asia-Pacific Perspective: Redefining Obeisty and its treatment. Health Communications Australia. [electronic article] 2000. Melburne

24. Bell AC, Ge K, Popkin BM. The road to obesity or the path to prevention: motorized transportation and obesity in China. Obes Res. 2002;10(4):277-283.

25. Qin L, Corpeleijn E, Jiang $\mathrm{C}$ et al. Physical activity, adiposity and diabetes risk in middleaged and older Chinese population: The Guangzhou Biobank cohort study. Diabetes Care. 2010.

26. Du SF, Mroz TA, Zhai FY, Popkin BM. Rapid income growth adversely affects diet quality in China particularly for the poor! Social Science \& Medicine. 2004;59(7):15051515.

27. Jones-Smith JC, Popkin BM. Understanding community context and adult health changes in China: development of an urbanicity scale. Soc Sci Med. 2010;71(8):1436-1446.

28. Mendez MA, Monteiro CA, Popkin BM. Overweight exceeds underweight among women in most developing countries. Am J Clin Nutr. 2005;81(3):714-721.

29. Canoy D, Buchan I. Challenges in obesity epidemiology. Obes Rev. 2007;8 Suppl 1:1-11.

30. McLaren L. Socioeconomic status and obesity. Epidemiologic Reviews. 2007;29:29-48. 
31. Monteiro CA, Conde WL, Popkin BM. Independent effects of income and education on the risk of obesity in the Brazilian adult population. Journal of Nutrition. 2001;131(3):881S-886S.

32. Monteiro CA, Moura EC, Conde WL, Popkin BM. Socioeconomic status and obesity in adult populations of developing countries: a review. Bulletin of the World Health Organization. 2004;82(12):940-946.

33. Popkin BM. Technology, transport, globalization and the nutrition transition food policy. Food Policy. 2006;31(6):554-569.

34. Lee SA, Wen WQ, Xu WH et al. Prevalence of obesity and correlations with lifestyle and dietary factors in Chinese men. Obesity. 2008;16(6):1440-1447.

35. Bauman A, Ma G, Cuevas F et al. Cross-national comparisons of socioeconomic differences in the prevalence of leisure-time and occupational physical activity, and active commuting in six Asia-Pacific countries. J Epidemiol Community Health. 2011;65(1):3543.

36. Bauman A, lman-Farinelli M, Huxley R, James WP. Leisure-time physical activity alone may not be a sufficient public health approach to prevent obesity--a focus

37. Zhai F, Wang H, Wang Z, Popkin BM, Chen C. Closing the energy gap to prevent weight gain in China. Obesity Reviews. 2008;9:107-112. 
Table 1. Characteristics of men and women according to the duration of possessing motorized vehicles, 1997-2006 (n=3,853)

\begin{tabular}{|c|c|c|c|c|c|c|c|c|}
\hline \multirow[b]{2}{*}{ Characteristics } & \multicolumn{3}{|c|}{ Men } & \multirow[b]{2}{*}{$P^{\mathrm{a}}$} & \multicolumn{3}{|c|}{ Women } & \multirow[b]{2}{*}{$P^{\mathrm{a}}$} \\
\hline & $\begin{array}{c}\text { Non-motorized } \\
(\mathrm{n}=856)\end{array}$ & $\begin{array}{c}\text { Motorized 1 5 years } \\
(\mathrm{n}=516)\end{array}$ & $\begin{array}{c}\text { Motorized }>5 \text { years } \\
(n=497)\end{array}$ & & $\begin{array}{c}\text { Non-motorized } \\
(\mathrm{n}=907)\end{array}$ & $\begin{array}{c}\text { Motorized 1 5 years } \\
(\mathrm{n}=543)\end{array}$ & $\begin{array}{c}\text { Motorized >5 years } \\
(\mathrm{n}=534)\end{array}$ & \\
\hline Participants (\%) & 45.8 & 27.6 & 26.6 & & 45.7 & 27.4 & 26.9 & \\
\hline Rural residence (\%) & 66.6 & 69.0 & 70.0 & 0.38 & 65.6 & 68.5 & 72.5 & 0.02 \\
\hline Age (year) & $46.6(11.0)$ & $44.8(11.6)$ & $45.6(9.9)$ & 0.05 & $46.7(9.9)$ & $46.2(10.1)$ & $46.9(8.8)$ & 0.71 \\
\hline Mean BMI at baseline $\left(\mathrm{kg} / \mathrm{m}^{2}\right)$ & $22.25(3.77)$ & $22.54(3.77)$ & $22.27(2.67)$ & 0.46 & $22.36(3.96)$ & $22.57(3.87)$ & $22.92(3.65)$ & 0.003 \\
\hline Mean BMI $\left(\mathrm{kg} / \mathrm{m}^{2}\right)$ & $22.90(4.22)$ & $23.26(4.07)$ & $23.43(3.81)$ & 0.01 & $22.92(3.56)$ & $23.70(4.01)$ & $23.86(3.56)$ & $<0.001$ \\
\hline Mean weight change (kg) & $1.3(9.2)$ & $1.8(9.7)$ & $2.9(5.7)$ & 0.04 & $1.7(8.1)$ & $2.2(8.3)$ & $2.2(7.3)$ & 0.63 \\
\hline Mean WC at baseline $(\mathrm{cm})$ & $77.6(8.9)$ & $78.2(10.0)$ & $78.8(8.8)$ & 0.002 & $75.2(8.5)$ & $75.6(9.1)$ & $76.0(9.3)$ & 0.01 \\
\hline Mean WC $(\mathrm{cm})$ & $80.6(10.7)$ & $81.4(11.6)$ & $81.9(13.1)$ & 0.03 & $78.3(10.1)$ & $78.9(12.0)$ & $79.2(12.4)$ & 0.14 \\
\hline Mean WC change $(\mathrm{cm})$ & $2.6(8.2)$ & $2.8(9.5)$ & $3.4(8.1)$ & 0.99 & $2.6(7.6)$ & $3.0(8.6)$ & $3.3(8.7)$ & 0.65 \\
\hline Obesity at baseline $(\%)^{\mathrm{b}}$ & 15.6 & 17.6 & 14.4 & 0.19 & 19.0 & 19.6 & 20.9 & 0.002 \\
\hline Obesity $(\%)^{\mathrm{b}}$ & 21.1 & 24.4 & 25.7 & 0.12 & 21.7 & 31.5 & 35.2 & $<0.001$ \\
\hline Abdominal obesity at baseline $(\%)^{\mathrm{c}}$ & 9.7 & 12.1 & 14.3 & 0.04 & 27.2 & 30.4 & 32.7 & 0.08 \\
\hline Abdominal obesity $(\%)^{\mathrm{c}}$ & 18.2 & 22.3 & 24.7 & 0.01 & 42.3 & 46.8 & 49.8 & 0.02 \\
\hline Daily energy intake (kcal) & 2572 & 2550 & 2590 & 0.66 & 2236 & 2224 & 2214 & 0.36 \\
\hline Daily fat intake (g) & 76.7 & 74.2 & 77.9 & 0.56 & 68.1 & 69.2 & 69.2 & 0.69 \\
\hline Carbohydrate intake (g) & 380.4 & 377.7 & 375.0 & 0.23 & 337.2 & 332.5 & 327.5 & 0.04 \\
\hline Protein (g) & 73.1 & 74.1 & 76.1 & 0.001 & 63.8 & 64.3 & 65.6 & 0.008 \\
\hline Leisure time physical activity (\%) & 16.7 & 12.8 & 14.5 & 0.37 & 7.9 & 4.4 & 6.0 & 0.04 \\
\hline \multicolumn{9}{|l|}{ Occupational physical activity (\%) } \\
\hline Light & 40.3 & 30.0 & 29.0 & & 38.8 & 28.4 & 32.5 & \\
\hline Middle & 28.5 & 35.4 & 35.4 & & 28.6 & 38.5 & 33.8 & \\
\hline Heavy & 31.1 & 34.6 & 35.6 & $<0.001$ & 32.5 & 33.1 & 33.6 & $<0.001$ \\
\hline \multicolumn{9}{|l|}{ Income $(\%)$} \\
\hline Low & 27.9 & 26.9 & 18.1 & & 26.6 & 27.1 & 20.2 & \\
\hline Low middle & 26.0 & 25.8 & 22.3 & & 23.8 & 24.9 & 27.5 & \\
\hline Upper middle & 23.8 & 22.1 & 30.0 & & 24.4 & 25.0 & 25.8 & \\
\hline High & 22.2 & 25.2 & 29.6 & 0.002 & 25.2 & 23.0 & 26.4 & 0.12 \\
\hline
\end{tabular}


Education $(\%)$

Low middle $\quad 35.3 \quad 47.3$

$\begin{array}{lll}\text { Upper middle } & 23.2 & 21.7\end{array}$

26.4

26.4

$49.7 \quad 26.5$

51.0

53.4

31.7

18.7

$<0.001$

3.8

$\begin{array}{cc}21.7 & 22.1 \\ 2.7 & 1.8\end{array}$

$7.5 \quad 2.7$

Continuous variables were presented as Mean (SD); categorical variables were presented as percenta

1.3

$<0.001$

tested in linear regression mode and adjusted for baseline age and follow-up years; $P$ values for categorical variables were tested with Chi-

square. ${ }^{\mathrm{b}}$ General obesity is $\mathrm{BMI} \geq 25 \mathrm{~kg} / \mathrm{m}^{2} .{ }^{\mathrm{c}}$ Abdominal obesity is $\mathrm{WC} \geq 90 \mathrm{~cm}$ for men and WC $\geq 80 \mathrm{~cm}$ for women. 
Table 2. The changes in body weight and waist circumference in men and women, 1997-2006 $(n=3,853)$

\begin{tabular}{|c|c|c|c|c|}
\hline \multirow[b]{2}{*}{ Factors } & \multicolumn{2}{|l|}{ Men } & \multicolumn{2}{|l|}{ Women } \\
\hline & $\begin{array}{c}\text { Weight change } \\
(\mathrm{kg})\end{array}$ & $\begin{array}{l}\text { Waist change } \\
(\mathrm{cm})\end{array}$ & $\begin{array}{c}\text { Weight change } \\
(\mathrm{kg})\end{array}$ & $\begin{array}{c}\text { Waist change } \\
(\mathrm{cm})\end{array}$ \\
\hline \multicolumn{5}{|l|}{ Motorization } \\
\hline Non-motorized & $1.3(0.5)$ & $2.6(0.5)$ & $1.5(0.4)$ & $2.8(0.5)$ \\
\hline Motorized 1 5 years & $2.1(0.6)^{*}$ & $3.0(0.6)$ & $2.2(0.6)^{*}$ & $3.1(0.6)$ \\
\hline Motorized > 5 years & $2.5(0.7)^{* *}$ & $3.6(0.7)^{* *}$ & $2.4(0.6)^{*}$ & $2.9(0.6)$ \\
\hline$P$ for trend & 0.006 & 0.017 & 0.008 & 0.76 \\
\hline \multicolumn{5}{|l|}{ Education } \\
\hline Low & $1.3(0.7)$ & $2.7(0.6)$ & $1.9(0.4)$ & $3.7(0.5)$ \\
\hline Low middle & $1.6(0.5)$ & $2.9(0.5)$ & $2.3(0.5)$ & $2.4(0.6)^{*}$ \\
\hline Upper middle & $2.6(0.8)^{*}$ & $3.3(0.7)$ & $1.3(0.8)$ & $1.6(0.8)^{* *}$ \\
\hline High & $4.1(1.7)^{* *}$ & $3.4(1.6)$ & $0.9(2.0)$ & $-0.5(2.1)^{* * *}$ \\
\hline$P$ for trend & 0.002 & 0.25 & 0.36 & $<0.001$ \\
\hline \multicolumn{5}{|l|}{ Income } \\
\hline Low & $1.4(0.7)$ & $2.9(0.7)$ & $1.3(0.6)$ & $2.7(0.6)$ \\
\hline Low middle & $1.3(0.7)$ & $2.7(0.7)$ & $1.7(0.6)$ & $3.1(0.6)$ \\
\hline Upper middle & $2.1(0.7)$ & $2.9(0.7)$ & $2.0(0.6)$ & $2.6(0.6)$ \\
\hline High & $2.6(0.7)^{*}$ & $3.3(0.7)$ & $2.7(0.6)^{* *}$ & $3.2(0.8)$ \\
\hline$P$ for trend & 0.012 & 0.43 & 0.003 & 0.63 \\
\hline \multicolumn{5}{|l|}{ Region } \\
\hline Urban & $1.9(0.6)$ & $2.7(0.6)$ & $1.8(0.6)$ & $2.7(0.6)$ \\
\hline Rural & $1.9(0.4)$ & $3.1(0.4)$ & $2.0(0.4)$ & $3.0(0.4)$ \\
\hline $\begin{array}{l}P \text { for trend } \\
\text { Occupational physical } \\
\text { activity }\end{array}$ & 0.97 & 0.27 & 0.58 & 0.46 \\
\hline Light & $2.4(0.6)$ & $3.9(0.6)$ & $2.2(0.5)$ & $3.1(0.6)$ \\
\hline Middle & $1.7(0.6)$ & $3.0(0.6)^{*}$ & $1.7(0.5)$ & $2.8(0.5)$ \\
\hline Heavy & $1.5(0.6)^{*}$ & $2.0(0.6)^{* * *}$ & $1.9(0.5)$ & $2.8(0.5)$ \\
\hline$P$ for trend & 0.052 & $<0.001$ & 0.54 & 0.49 \\
\hline
\end{tabular}

Model adjusted for baseline weight, height, age and WC (for waist change), follow-up time, total energy and fat intake. For men, model additionally adjusted for smoking and alcohol drinking. Depending on the dependent variable, model was also adjusted for motorization, education, income, living region and occupational physical activity

$* P<0.05 * * P<0.01 * * * P<0.001$ 
Table 3. The association between motorization and current adiposity in men and women, $2006(n=3,853)$

\begin{tabular}{|c|c|c|c|c|c|c|c|c|}
\hline \multirow[b]{2}{*}{ Motorization } & \multicolumn{4}{|c|}{ Men } & \multicolumn{4}{|c|}{ Women } \\
\hline & $\begin{array}{c}\text { Mean BMI } \\
\left(\mathrm{kg} / \mathrm{m}^{2}\right)\end{array}$ & $\begin{array}{c}\text { Obesity } \\
\text { OR }(95 \% \mathrm{CI}) \\
\end{array}$ & $\begin{array}{c}\text { Mean WC } \\
(\mathrm{cm})\end{array}$ & $\begin{array}{c}\text { Abdominal } \\
\text { obesity } \\
\text { OR }(95 \% \mathrm{CI}) \\
\end{array}$ & $\begin{array}{c}\text { Mean BMI } \\
\left(\mathrm{kg} / \mathrm{m}^{2}\right)\end{array}$ & $\begin{array}{c}\text { Obesity } \\
\text { OR }(95 \% \mathrm{CI}) \\
\end{array}$ & $\begin{array}{c}\text { Mean WC } \\
(\mathrm{cm})\end{array}$ & $\begin{array}{c}\text { Abdominal } \\
\text { obesity } \\
\text { OR }(95 \% \mathrm{CI}) \\
\end{array}$ \\
\hline Non-motorized & $22.96(0.28)$ & Ref & $80.9(0.7)$ & Ref & $22.97(0.24)$ & Ref & $79.2(0.6)$ & Ref \\
\hline Motorized 1 5 years & $23.37(0.35)$ & $1.35(1.02-1.79)$ & $81.5(0.9)$ & $1.34(0.97-1.87)$ & $23.74(0.31)^{* * *}$ & $1.68(1.32-2.15)$ & $78.5(0.9)$ & $0.90(0.69-1.18)$ \\
\hline Motorized > 5 years & $23.28(0.37)$ & $1.30(0.97-1.74)$ & $81.8(0.9)$ & $1.38(0.99-1.94)$ & $23.73(0.32)^{* * *}$ & $1.93(1.50-2.49)$ & $78.2(0.8)$ & $0.89(0.67-1.17)$ \\
\hline$P$ for trend & 0.13 & 0.054 & 0.13 & 0.047 & $<0.001$ & $<0.001$ & 0.058 & 0.37 \\
\hline
\end{tabular}

BMI, WC and adiposity were measured at the end of follow-up. Model adjusted for baseline age, follow-up time, total energy and fat intake, and current

BMI (for WC and abdominal obesity). For men, model additionally adjusted for smoking and alcohol drinking. Depending on the dependent

variable, model was also adjusted for motorization, income, education, living region and occupational physical activity. $* P<0.05 * * P<0.01$

*** $P<0.001$ 

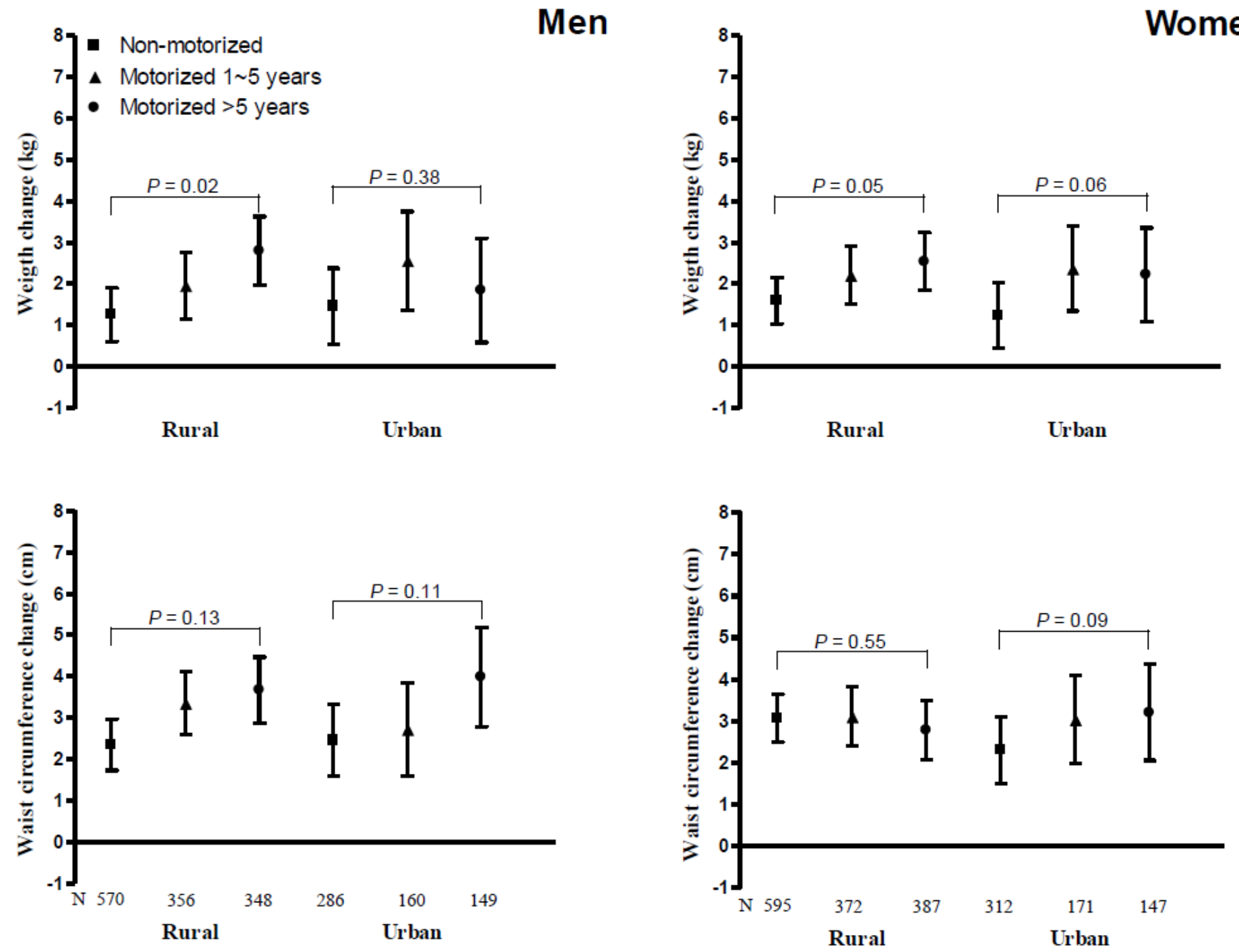

Figure 1. 

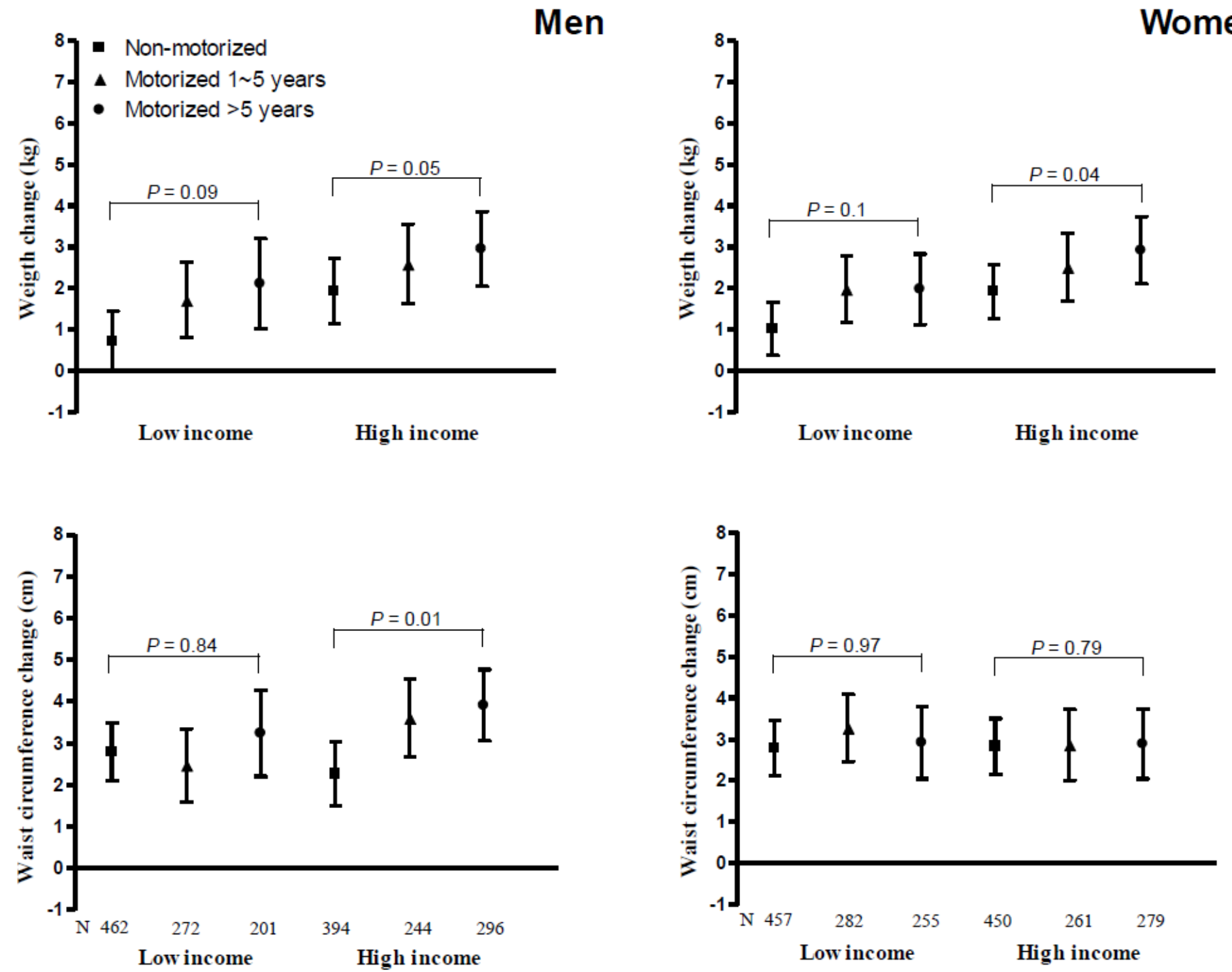

Figure 2. 